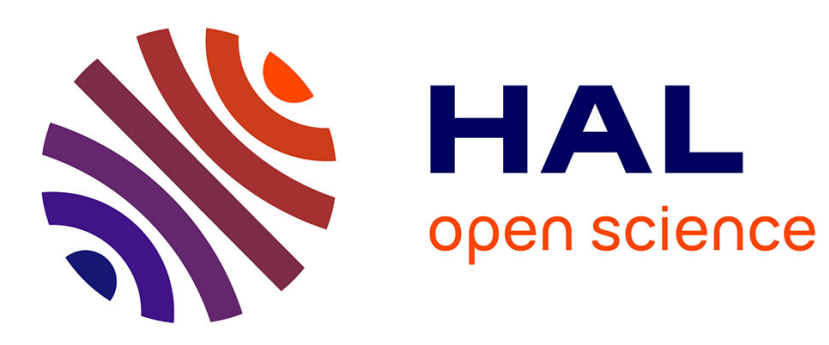

\title{
R-L-C model of an Inverter DC bus for diagnosis purpose
}

Cyrille Gillot, Hamed Yahoui, Gérard Rojat, Riccardo Scorretti

\section{To cite this version:}

Cyrille Gillot, Hamed Yahoui, Gérard Rojat, Riccardo Scorretti. R-L-C model of an Inverter DC bus for diagnosis purpose. IEEE ISIE, Jun 2007, Vigo, Spain. pp.850 - 853, 10.1109/ISIE.2007.4374708 . hal-00369579

\section{HAL Id: hal-00369579 https://hal.science/hal-00369579}

Submitted on 3 Jun 2009

HAL is a multi-disciplinary open access archive for the deposit and dissemination of scientific research documents, whether they are published or not. The documents may come from teaching and research institutions in France or abroad, or from public or private research centers.
L'archive ouverte pluridisciplinaire HAL, est destinée au dépôt et à la diffusion de documents scientifiques de niveau recherche, publiés ou non, émanant des établissements d'enseignement et de recherche français ou étrangers, des laboratoires publics ou privés. 


\title{
R-L-C model of an Inverter DC bus for diagnosis purpose
}

\author{
Cyrille Gillot ${ }^{1}$, Hamed Yahoui $^{2}$, Gerard Rojat ${ }^{3}$, Ricardo Scorretti ${ }^{4}$ \\ Université de Lyon, Lyon, F-69622, France ; AMPERE CNRS, UMR5005 \\ ${ }^{1}$ Cyrille Gillot, e-mail : gillot@cegely.univ-lyon1.fr, ${ }^{2}$ Hamed Yahoui, e-mail : hamed.yahoui@univ-lyon1.fr, ${ }^{3}$ Gerard Rojat, \\ e-mail : gerard.rojat@univ-lyon1.fr, ${ }^{4}$ Ricardo Scorretti, e-mail : ricardo.scorretti@univ-lyon1.fr
}

\begin{abstract}
In this paper, the authors present the modelling of the impedance variation of an inverter DC bus. Modelling is done by application of the PEEC method (Partial Element Equivalent Circuit) with an additional method for computing the local charge density (analytical formulas) in order to give the local capacity. This method has been implemented so as to extract the behaviour of the local charge density, specifically for busbar structure. Results obtained in the case of an approached busbar equivalent geometry are shown. A quantification of the edges importance for the charge repartition is presented, and so its link with the HF local capacitor influence. Moreover simulations of the values of the global DC bus impedance versus frequency are compared to measures.
\end{abstract}

\section{INTRODUCTION}

Several methods are nowadays proposed to diagnose motor defects by current analysis with Fourier Transform method. In our project we present an analysis of the inverter DC bus in order to develop a new diagnostic method by the electromagnetic field measurement [1]. Actually, the power of the electrical drives flows through the bus-bar, for this reason, characteristics signals of both inverter and load can be extract of this DC bus. I we want to know where is the maximum signal of the emitted electromagnetic field, it is important to give a model of the DC bus frequency current components repartition.

The Partial Element Equivalent Circuit (PEEC) approach [2-3] is currently widespread so as to modelize the inverter bus bar. Unfortunately doesn't take into account the capacitance phenomenon. So as to include this aspect, some methods have been already developed, but less complicated approaches are needed. Following the work done in [4], this work extends the method to the computation of the local capacitance between the two parts of the DC bus. Actually, the power of the electrical drives flows through the bus-bar, for this reason, characteristics signals of both inverter and load can be extract of this DC bus. Its voltage can also be considered as constant, having regard to its filter electrolytic capacitor. Thus, quasi all signal signatures appears in the dc bus current.

For the range of the dozen of $\mathrm{kW}$ inverters, the DC bus geometry is rather complex, as shown in Fig. 1.

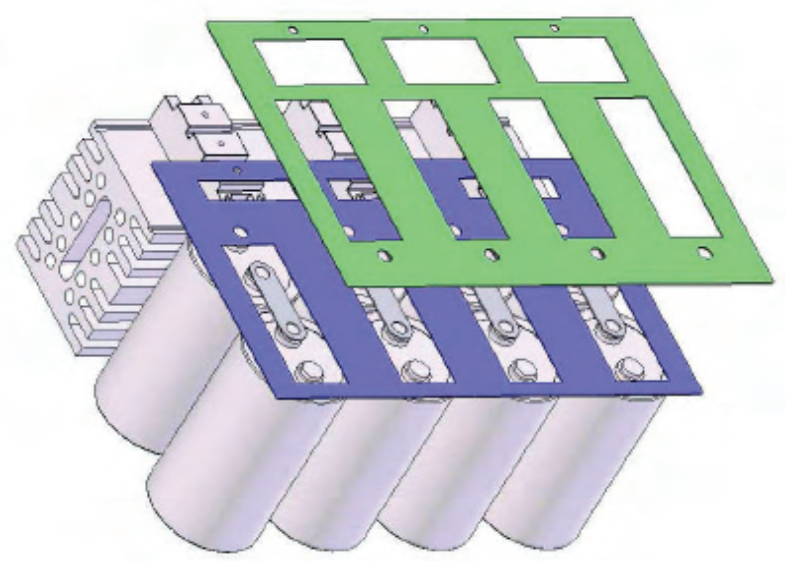

Fig. 1: real DC bus of a $55 \mathrm{~kW}$ inverter

\section{II - BASIC PEEC MODELLING AND EXTENSION TO THE MOMENT METHOD}

The Partial Element Equivalent Circuit - PEEC - model, introduce by A.E. Ruehli [3] in the seventies, is widely used nowadays so as to obtain an electrical equivalent circuit of a set of conductors. This method extracts resistive $(\mathrm{R})$, mutual inductive (Lp) partial electrical elements. In its theoretical development the (Lp, C, R) PEEC method takes into account the capacitive effect; however this effect is neglected in the basic (Lp, R) PEEC model, mostly because it is much more delicate to implement.

The fundamental (Lp, C, R) PEEC equation is;

$$
E=\frac{J}{\sigma}=E_{0}-\frac{\partial A}{\partial t}-\nabla \phi
$$

This equation is based on the superposition of all the sources that create an electrical field in a conductor. The three right terms in (1) represent respectively the imposed electrical field E0 (considered zero), the time derivative of the magnetic vector potential $\mathrm{A}$ and the gradient of the electric scalar potential $\psi$. After having discretized the conductors, the unknowns present in (1) are the discrete current density distribution $\mathrm{J}_{\mathrm{k}}$ and the discrete charge density distribution $\rho k$.

This last term, which is responsible for taking into account the capacitive effect, can be problematic for complex geometries, or quite complex to implement; thus, it is usually neglected in low frequencies applications modelling of PEEC method. However, (Lp,R) PEEC model yields incor- 
rect predictions of damping or losses that occur at high frequencies or for obviously capacitive dominant systems. Anyway, variants of solvers for (1) exist so as to focus more specifically on one or other interesting physical phenomena intrinsic to the problem; Thus, the authors propose here to simply couple it with a partial capacitance distribution issue of a MoM (Method of Moments) partial charge calculus. The study of the partial inter-nodes capacitances values regarding its localisation Fig. 2 in the geometry and the degrees of discretization is presented.

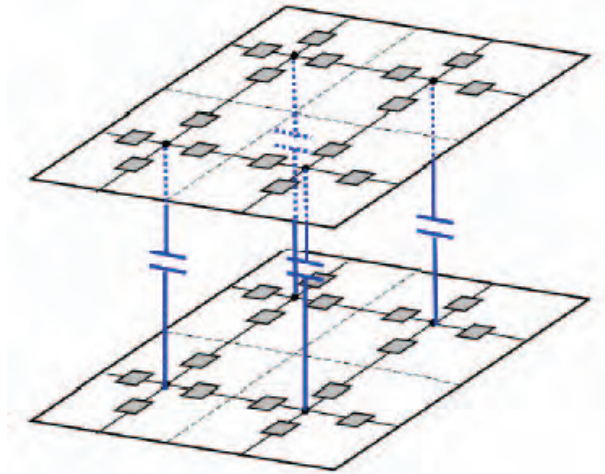

Fig. 2. Resistive, mutual inductive 2D electrical PEEC model coupled with inter conductor discrete partial capacitances.

These measures will also be used for the validation of the modelling methods by spatial geometry discretization.

One traditional way so as to extract the partial charge density of a discretized conductor geometry is to use the Moment Method (MoM). This method allows to solve any inhomogeneous differential equation (2) of the type:

$$
\hat{L}(f)=\phi
$$

Where $\hat{L}$ is a linear operator, $\phi$ is a known function

$f$ is the unknown function to be determined.

The starting point in the charge density calculation is the equation that gives the potential $\mathrm{Vi}$ of a conductor $\mathrm{i}$ as a function of the surface charge density $\rho$ i of the surrounding conductors, and the distance between the conductors $i$ and $\mathrm{j}$. For $\mathrm{k}$ conductors, this equation is:

$$
k_{i j}=\frac{\rho}{4 \pi \varepsilon_{0} S_{j}} \int_{s_{j}} \frac{d s_{j}}{r_{i j}}
$$

However, this coefficient raise problem as most of the time its computation is based on numerical methods, indeed for too much complicated geometries and in the case that the length $\mathrm{ri}$ becomes null the numerical integration diverge. For the case when the knowledge of the exact charge repartition and so the exact capacitance value is not critical, the global capacitance can be estimated with the planar capacitance formula:

$$
C g=\varepsilon 0 \frac{S}{e}
$$

Which lead For low frequency uses or low capacitive busbar geometries to :

$$
Q_{g}=C_{g} V
$$

Much more mathematical information on this widespread method are given in [5], [6], and [7].

The charge distribution is closely knit with the electric field behavior on the edges (Fig. 3 and 4). Globally, the electric field increases on the external edges of the conductors.

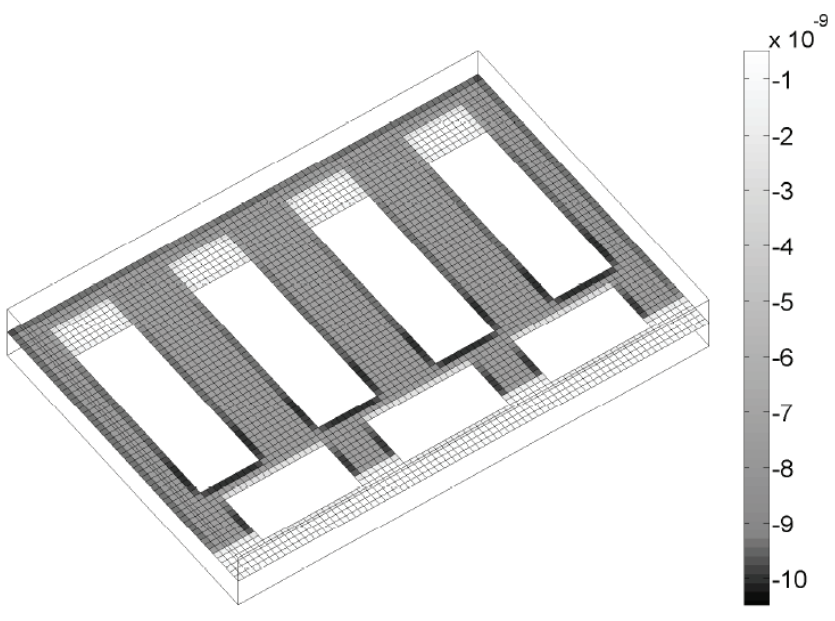

Fig. 3 Charge density repartition on the inner surface of the bus bar negative conductor (in Coulomb $/ \mathrm{m}^{2}$ ).

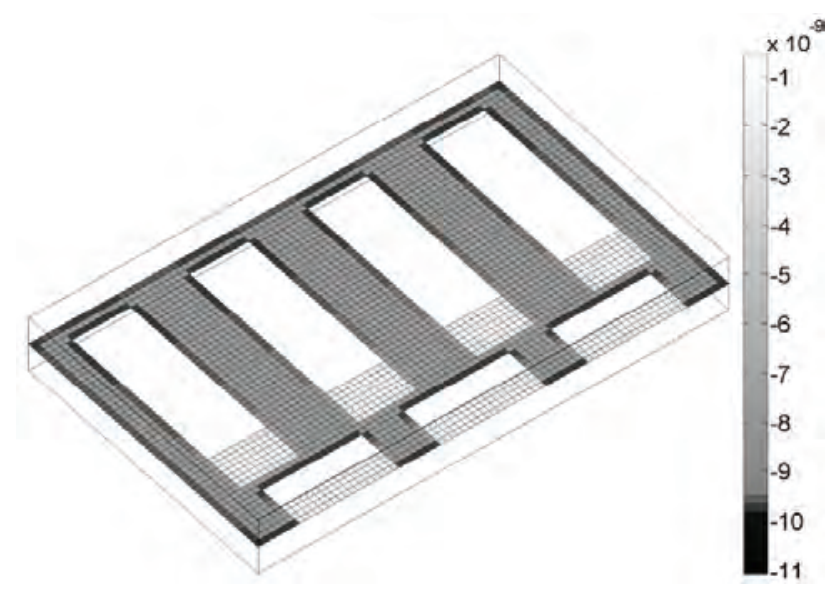

Fig. 4 Charge density repartition on the inner surface of the bus bar top conductor (in Coulomb $/ \mathrm{m}^{2}$ ) with $3 \mathrm{~mm}$ of thickness.

\section{GLOBAL CAPACITY MEASUREMENT}

To put the stress on the corner effect, we have calculated the global capacity between negative and positive plates. The simplified bus is made with two square plates by 400 mm aside (Fig. 5). We have applied this method to a DC bus made with two dummy aluminium plates. 


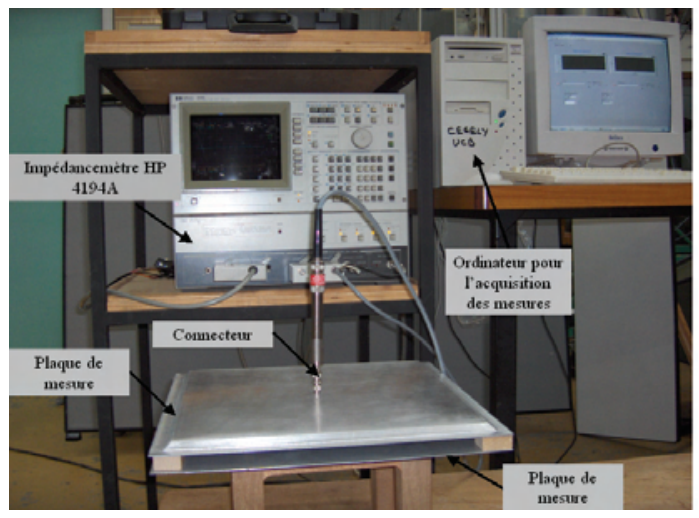

Fig. 5: test bench

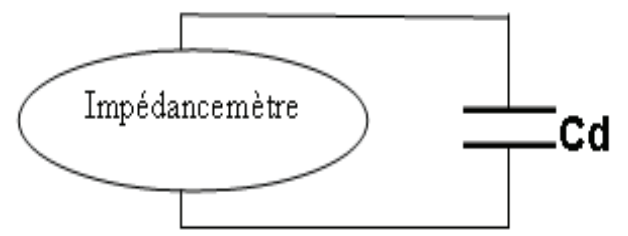

Fig. 6 : experimental simplified DC bus -Impedance measurement

In a first step the capacity $\mathrm{Cd}$ has been calculated by the well known analytical formula (4). The resulting values obtained by the analytical formula are given in the following table 1:

Table 1: computing the analytical value of the capacity
\begin{tabular}{|c|c|}
\hline & Capacity \\
\hline Analytic formula & $1.42 \mathrm{nF}$ \\
\hline
\end{tabular}

The resulting values obtained by the impedance meter (Fig. 6) are given in the following fig. 7 versus the frequencv:

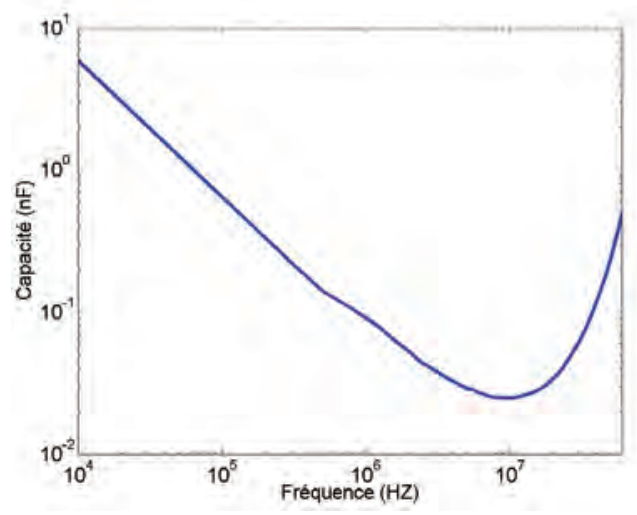

Fig. 7: Equivalent capacity versus the frequency for $1 \mathrm{~mm}$ of thickness.

The comparison between the analytical value and the measured one (at high frequency) can be easier explain by the assumption that the corner field effect is not taking account in the analytical formula (the corner effect increase the apparent capacity). As most the frequency is increasing as most the variation the electric field increases on the external edges of the conductors.

\section{APPLICATION TO THE DIAGNOSTIC OF AN ELECTRICAL DRIVES}

In our project we want to use the inverter DC bus in order to develop a new diagnostic method by the analysis electromagnetic field measurement. Actually, the power of the electrical drives flows through the bus-bar, for this reason, characteristics signals of both inverter and load can be extract of this DC bus. I we want to know where is the maximum signal of the emitted electromagnetic field, it is important to give a model of the DC bus frequency current components repartition.

These measures have been made with a constant load torque of $10 \mathrm{~N}$.m. with a superposed variable load at $5 \mathrm{~Hz}$ and $9 \mathrm{~Hz}$. the load torque frequency distinctly emerges in Fig. 8 (respectively in Fig. 9).

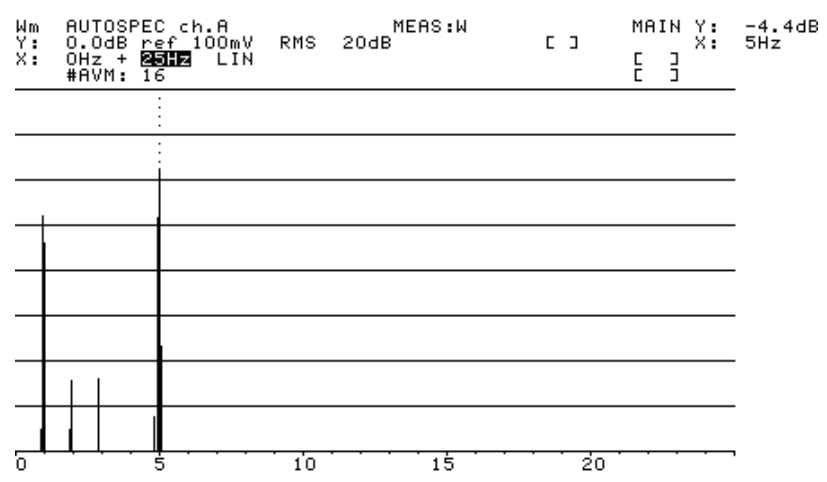

Fig. 8. Effect of a sinusoidal load torque at $5 \mathrm{~Hz}$ on the DC bus magnetic field signature.

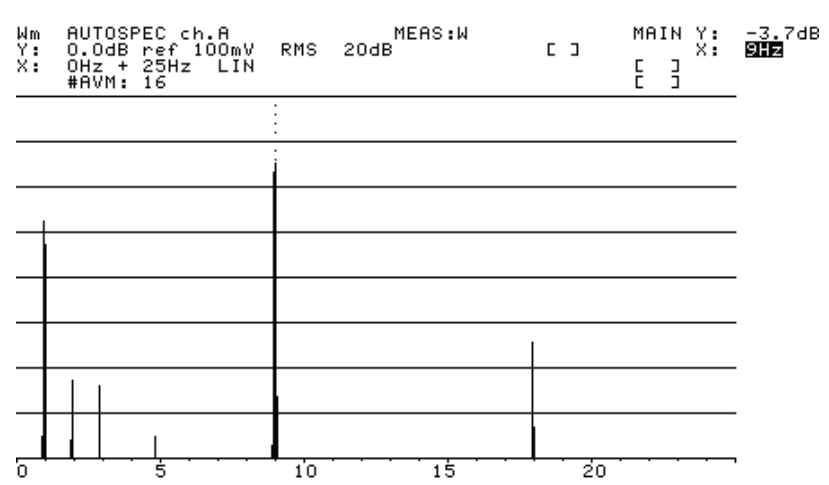

Fig. 9. Effects of a sinusoidal load torque at $9 \mathrm{~Hz}$ on the DC bus magnetic field signature

The application test [8] has been made on a $5.5 \mathrm{~kW}$ induction machine fid by an inverter whose fundamental stator frequency in operation was chosen to be equal to $f \mathrm{~s}=43$ $\mathrm{Hz}$. This particular value allows measurement to be independent of the natural $50 \mathrm{~Hz}$ power supply frequency. 


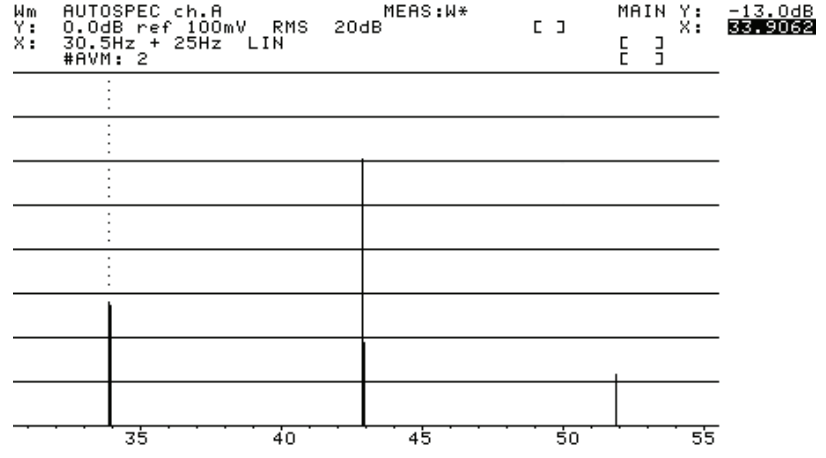

Fig. 10. Harmonics around the fundamental stator frequency in case of a sinusoidal load torque at $9 \mathrm{~Hz}$.

In the same way, modulations of the low frequency, due to the time varying load, are created around the fundamental stator frequency, as represented in Fig. 10 with $9 \mathrm{~Hz}$.

\section{CONCLUSION}

A method to map the electrical charge repartition on the surface of a simplified DC bus has been presented. The electric field increases on the external edges of the conductors and becomes maximum on a double edge discontinuity. The variation of global capacity measured versus the frequency has underlined the corner effect on a dummy plates DC bus system. The frequency spectral analysis of this magnetic field measured at a specific place above the inverter DC bus provides significant signal signature. Information not only on the inverter but also on the induction machine and its load are present and exploitable in future diagnostic schemes.

\section{REFERENCES}

[1] C. Gillot, H. Yahoui and G. Rojat "Analyse du champ magnétique proche émis par un bus barre" Revue Internationale de Génie Electrique - RIGE - 2007.

[2] A. Guena, Ph.D. Thesis, Ecole Normale Supérieure de Cachan, France, 2000

[3] A. Ruehli, U. Miekkla, A. Bellen, and H. Heeb, "Stable time domain solutions of EMC problems using PEEC circuit models", in Proc. Int. Symp. Electromagnetic Compatibility, Chicago, IL, Aug, 1994, pp. 371-373.

[4] C. Gillot, H. Yahoui, G. Rojat Fine magnetic field prospecting of an inverter dc bus, IEEE ISIE04 (International symposium on Industrial Electronics), Ajaccio 4-7 mai 2004.

[5] R. Harrington, Field Computation by Moment Methods. Syracuse University: IEEE Press Series on Electromagnetic Waves, 1993.

[6] L. Tsai and C. Smith, "Moment methods in electromagnetics forundergraduates," IEEE Transactions on Education, vol. E-21, no.1, pp. 14-22, 1978.

[7] P. Bancroft, Understanding electromagnetic scattering using the moment method. Boston: Artech House Publishers, 1996.

[8] C. Gillot, H. Yahoui, G. Rojat, 'Power drive analysis for diagnostic purpose by inverter DC bus magnetic field measures", IEEE IECON06, Paris, 7-10 november 2006. 